\title{
Echolocation in Oilbirds and swiftlets
}

\section{Signe Brinkløv ${ }^{1 *}$, M. Brock Fenton ${ }^{1}$ and John M. Ratcliffe ${ }^{2}$}

1 Department of Biology, Western University, London, ON, Canada

2 Institute of Biology, University of Southern Denmark, Odense, Denmark

\section{Edited by:}

Mariana L. Melcón, Fundación

Cethus, Argentina

Reviewed by:

Noritaka Ichinohe, National Institute

of Neuroscience, Japan

Lore Thaler, Durham University, UK

${ }^{*}$ Correspondence:

Signe Brinkløv, Department of Biology, Western University,

1151 Richmond Street, London, ON N6A 3K7, Canada.

e-mail:brinklov@biology.sdu.dk
The discovery of ultrasonic bat echolocation prompted a wide search for other animal biosonar systems, which yielded, among few others, two avian groups. One, the South American Oilbird (Steatornis caripensis: Caprimulgiformes), is nocturnal and eats fruit. The other is a selection of diurnal, insect-eating swiftlets (species in the genera Aerodramus and Collocalia: Apodidae) from across the Indo-Pacific. Bird echolocation is restricted to lower frequencies audible to humans, implying a system of poorer resolution than the ultrasonic (>20 kHz) biosonar of most bats and toothed whales. As such, bird echolocation has been labeled crude or rudimentary. Yet, echolocation is found in at least 16 extant bird species and has evolved several times in avian lineages. Birds use their syringes to produce broadband click-type biosonar signals that allow them to nest in dark caves and tunnels, probably with less predation pressure. There are ongoing discrepancies about several details of bird echolocation, from signal design to the question about whether echolocation is used during foraging. It remains to be seen if bird echolocation is as sophisticated as that of tongue-clicking rousette bats. Bird echolocation performance appears to be superior to that of blind humans using signals of notable similarity. However, no apparent specializations have been found so far in the birds' auditory system (from middle ear to higher processing centers). The advent of light-weight recording equipment and custom software for examining signals and reconstructing flight paths now provides the potential to study the echolocation behavior of birds in more detail and resolve such issues.

Keywords: Oilbird, Steatornis caripensis, swiftlets, Aerodramus, Collocalia, echolocation, biosonar, click

\section{INTRODUCTION}

In 1794, Lazzaro Spallanzani reported that blinded bats oriented in complete darkness, and, except for the fluttering of their wings, did so silently. Almost 20 years later, Alexander von Humboldt entered a cave in Venezuela and heard resident Oilbirds (Steatornis caripensis, von Humboldt, 1817) clicking noisily as they flew around in the cave that served as the birds' day roost. Had the two men corresponded, the behavior of von Humboldt's Oilbirds might have provided Spallanzani with the clue required to solve his famous bat puzzle, and brought ahead the study of animal sonar (echolocation) by about 135 years. We now know that Spallanzani's "silent" bats and von Humboldt's clicking birds use the same sensory mechanism, negotiating their surroundings via echo-feedback from self-emitted sounds. One key difference being that most echolocating bats operate using ultrasonic frequencies above the human hearing range $(>20 \mathrm{kHz})$ and undetectable by eighteenth and nineteenth century technology. Since Griffin's discovery of biosonar using ultrasonic sound above the range of human hearing [reviewed in Griffin (1958)], it has become evident that toothed whales also use echolocation to negotiate their underwater habitat and detect and track their prey (Kellogg and Kohler, 1952; Norris et al., 1961).

Animal sonar is not, however, synonymous with ultrasound. Echolocation signals of several bat and odontocete species include frequencies well below the $20 \mathrm{kHz}$ limit of human hearing
(Leonard and Fenton, 1984; Rydell and Arlettaz, 1994; Møhl et al., 2003). Echolocation based in part or entirely on audible signals has also been demonstrated in three species of Old World fruit bats (Rousettus aegyptiacus, $R$. leschenaulti, and $R$. amplexicaudatus) within the otherwise non-echolocating family Pteropodidae (Möhres and Kulzer, 1956; Novick, 1958). Certain tenrecs (Tenrecidae) from Madagascar (Gould, 1965), several species of shrew (Soricidae) (Gould et al., 1964; Buchler, 1976; Tomasi, 1979; Forsman and Malmquist, 1988; Siemers et al., 2009) and some blind people (Supa et al., 1944; Griffin, 1958; Thaler et al., 2011) also echolocate with signals of frequencies below $20 \mathrm{kHz}$.

The only non-mammalian echolocators discovered to date are two groups of birds (Figure 1), the Oilbird (Steatornithidae, Caprimulgiformes) and several species of swiftlets (Apodiformes, Apodidae, Collocalliini, Aerodramus spp. and Collocalia troglodytes). Given the benefits of biosonar under conditions of poor visibility, seals and owls had been proposed as possible echolocators (e.g., Poulter, 1963; Renoulf and Davies, 1982) but neither echolocate (Crafford and Ferguson, 1999; Schusterman et al., 2000). Why echolocation has evolved in some disparately related groups, but not in others, remains a tantalizing question, suggesting that ecological factors play a greater role in its evolution than physiological constraints and opportunities.

Echolocation research over the last 25 years has focused on the biosonar systems of bats and odontocetes. The few published 


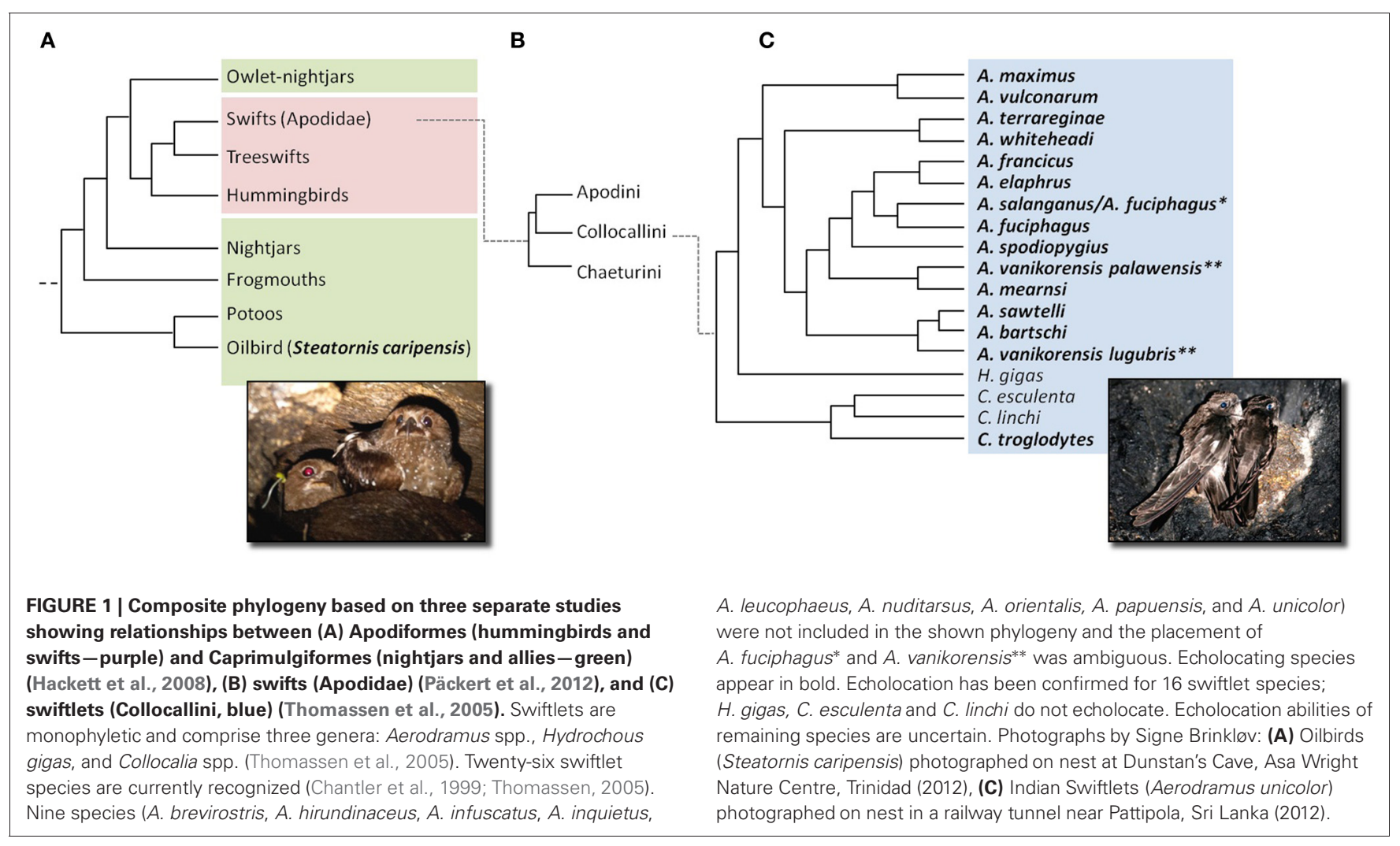

studies of bird echolocation provide important neuroethological insight and background (Griffin and Suthers, 1970; Fenton, 1975; Konishi and Knudsen, 1979; Griffin and Thompson, 1982; Thompson and Suthers, 1983; Coles et al., 1987; Thomassen et al., 2004; Thomassen and Povel, 2006) but also emphasize that there are many unresolved questions. We suggest that bird echolocation, while almost certainly not as specialized as that of bats and whales, holds the untapped potential for basic research on echolocation using sounds audible to humans, as well as for practical applications such as acoustic monitoring for conservation and management of these often vulnerable birds. Light-weight, stateof-the art field technology now available for the study of bat sonar should be readily applicable to the study of bird echolocation and should help to overcome the challenge of working in remote settings.

Here we review the sensory ecology of echolocating birds, emphasizing several outstanding questions. We consider the design of the birds' echolocation signals, their hearing, and their foraging and roosting behavior. We also speculate about the function and evolution of echolocation in birds and compare it to its use in bats and toothed whales. We further consider why most groups of echolocators, including the birds, use click-type signals rather than the frequency-modulated, often multi-harmonic, signals used by today's laryngeal echolocating bats.

\section{ECOLOGY OF ECHOLOCATING BIRDS OILBIRD ECOLOGY}

Oilbirds (Figure 1) roost in natural caves, primarily in tropical forest across NW South America and Trinidad from sea level to $3400 \mathrm{~m}$ (Thomas, 1999). Most other caprimulgids (e.g., night hawks and nightjars) are predominantly insectivorous, crepuscular foragers relying on vision to detect and track prey. Oilbirds are nocturnal fruit-eaters, preferentially eating fruits of palms (Palmaceae), laurels (Lauraceae), and incense (Burseraceae). They swallow the fruits whole (up to $6 \times 3 \mathrm{~cm}$ ), digest the pericarp, and regurgitate the seeds (Snow, 1961, 1962; Bosque et al., 1995). A recent GPS-tracking study from Caripe in Venezuela reported that the birds often spend the day outside their roosting cave, sitting quietly in trees (Holland et al., 2009). Detailed accounts of Oilbird ecology are found in Snow $(1961,1962)$ and Roca (1994).

Briefly, Oilbirds are large (ca. $400 \mathrm{~g}$, body length $45 \mathrm{~cm}$ beaktip of tail, wing span up to $1 \mathrm{~m}$ ) and capable of slow, maneuverable flight, with estimated flight speeds of $0.5-7 \mathrm{~m} / \mathrm{s}$, and of hovering in narrow spaces (Snow, 1961). Like other caprimulgids, Oilbirds have large eyes relative to their head size (Figure 1) but smaller than those of owls (Warrant, 2008). Oilbirds and owls have similar, low F-numbers (ratio of focal length to pupil diameter) indicating good visual sensitivity (Warrant, 2008). Remarkably, Oilbirds possess a banked retina with rod receptors arranged in a 3-layered structure, conferring a much higher rod to cone ratio than in owls (Warrant, 2008) with higher rod density $\left(\sim 1,000,000 \mathrm{~mm}^{-2}\right)$ than any other vertebrate (Martin et al., 2004). This may confer Oilbirds greater visual sensitivity in low-light conditions than owls. Whether this highly sensitive vision trades off spatial resolution remains to be determined (Warrant, 2008). Oilbirds appear to depend primarily on vision whenever possible as evidenced by observations that the incidence 
of sonar click emissions declines on brightly moonlit nights or in the presence of artificial light sources (Griffin, 1953; Konishi and Knudsen, 1979; Signe Brinkløv and John M. Ratcliffe, pers. obs.). Tapeta lucida occur in the eyes of some caprimulgids (Nicol and Arnott, 1974) but apparently not in Oilbirds (Martin et al., 2004). Oilbirds have large, heavily innervated olfactory organs, suggesting that sense of smell plays an important role in foraging. The birds' own musty odor may play a role in individual recognition (Snow, 1961). Like other caprimulgids, Oilbirds have long rictal bristles around the beak, which may have a close-range tactile function (Snow, 1961).

\section{SWIFTLET ECOLOGY}

Swiftlets are monophyletic (Thomassen et al., 2003, 2005; Price et al., 2004; Hackett et al., 2008) comprising approximately 26 species (Apodiformes, Apodidae). Swiftlets are found across the Indo-Pacific region, from the Seychelles and Mascarenes in the Indian Ocean to Tahiti, Mo'orea and the Marquesas in the South Pacific (Chantler et al., 1999; Thomassen, 2005). Numerous subspecies have been identified but swiftlet phylogenetic relationships are not fully resolved (Thomassen et al., 2005). This reflects a lack of distinguishing morphological and nest characteristics as well as incomplete phylogenetic sampling (Chantler et al., 1999). An attempt to use echolocation as a discriminative character to split swiftlets into echolocating (Aerodramus) and non-echolocating (Collocalia and Hydrochous) genera (Brooke, 1970, 1972; Medway and Pye, 1977) was refuted because Pygmy Swiftlets (C. troglodytes) also echolocate (Price et al., 2004). Only further research will determine whether or not the Aerodramus and Collocalia genera are justified and will be maintained (Thomassen et al., 2005).

Swiftlets are much smaller $(\sim 10 \mathrm{~g})$ than Oilbirds and all species have long, narrow wings (Chantler et al., 1999), characteristic of the typical fast flight of other apodids (Lack, 1956; Videler et al., 2004). Swiftlets are mainly diurnal foragers and hunt small insects on the wing (Chantler et al., 1999; Fullard et al., 2010). At night they typically roost in nests located on the walls of natural caves or mines and tunnels, but intriguingly, there are some published observations of nocturnal activity, including feeding, by some swiftlet species outside their cave roosts (Fullard et al., 1993; Chantler et al., 1999; Price et al., 2005). Swiftlet nests are constructed and glued in place with the birds' own saliva and nests of several species are collected for "birds' nest soup," a billion dollar industry fueled by human demand (Chantler et al., 1999).

Similar to the situation for bats within the Rousettus genus (Giannini and Simmons, 2003), not all swiftlets echolocate. Echolocation has been confirmed in some species, dismissed in others, and for some species we simply do not know. While Hydrochous gigas, Collocalia esculenta, and C. linchi (Figure 1) do not echolocate (Cranbrook and Medway, 1965; Medway and Wells, 1969; Fenton, 1975), at least 16 other swiftlet species do (C. troglodytes, Aerodramus elaphrus, A. francicus, A. salanganus, A. bartschi (Price et al., 2004); A. vanikorensis, (Griffin and Suthers, 1970); A. brevirostris, A. fuciphagus, A. maximus, A. vulcanorum, A. terrareginae (Thomassen et al., 2004); A. sawtelli (Fullard et al., 1993); A. spodiopygius (Griffin and Thompson, 1982); A. papuensis (Price et al.,
2005); A. hirundinaceus, A. unicolor (Chantler et al., 1999; Signe Brinkløv, pers. obs.). Echolocation abilities of additional species (A. nuditarsus, A. inquietus, A. leucophaeus, A. whiteheadi, A. pelewensis, A. orientalis, A. mearnsi, and A. infuscatus) are assumed, but remain unconfirmed (Chantler et al., 1999). Swiftlets have relatively large eyes for their body size and they appear to use vision even in low-light conditions (Thomassen, 2005). We were unable to find quantitative data on the visual acuity of swiftlets.

\section{BIOSONAR SOUND PRODUCTION PHYSIOLOGY IN ECHOLOCATING BIRDS}

Birds produce their echolocation signals in the syrinx, the vocal organ specific to birds and found near to where the trachea forks into the lungs. The production mechanism for echolocation signals has been studied in one species of swiftlet with a tracheobronchial syrinx (Suthers and Hector, 1982; Thomassen, 2005), and in the Oilbird, which has a bronchial and bilaterally asymmetric syrinx (Griffin, 1944; Suthers and Hector, 1985). No direct observations have been made of the syringes of either Oilbirds or swiftlets, and the following description may need revision in light of more recent work on bird vocal production physiology (Goller and Larsen, 1997; Elemans et al., 2004; Thomassen, 2005).

With these caveats in mind, phonation (clicks and other acoustic signals) in both groups is driven by subsyringeal pressure, initiated during expiration, and controlled by two antagonistic muscle pairs. Contraction of an extrinsic muscle pair ( $\mathrm{mm}$. sternotrachealis) folds the external tympaniform membranes into the syrinx (or the two half-syringes in Oilbirds) lumen toward the internal tympaniform membranes. The membranes are then set into vibration by the expiratory airflow. In Oilbirds, clicks are actively terminated by contraction of the single pair of intrinsic syringeal muscles ( $\mathrm{mm}$. broncholateralis). In contrast, the social vocalizations of Oilbirds are terminated passively by relaxation of the sternotrachealis muscles (Suthers and Hector, 1985). Swiftlets lack intrinsic syringeal muscles and terminate their clicks by contraction of extrinsic tracheolateralis muscles (Suthers and Hector, 1982; Thomassen, 2005). Most species of echolocating swiftlet produce single clicks as well as double clicks (two single clicks in quick succession, as described below). The pause between two clicks within a click-pair may be caused by a brief blocking of airflow through the syrinx as the external and internal tympaniform membranes touch. Single clicks appear to arise when the membranes are pulled together before the expiratory airflow generates enough pressure to initiate vibration of the membranes (Suthers and Hector, 1982). Both sides of the swiftlet syrinx appear able to contribute to each member of a click-pair; that is, birds can still emit double clicks even if one side of the syrinx is plugged (Suthers and Hector, 1982).

\section{BIOSONAR SIGNAL DESIGN IN ECHOLOCATING BIRDS}

Echolocation behavior involves the same operating principles across animal groups, namely extracting information about the immediate surroundings from returning echoes of one's own signals. However, vocal physiology, mechanisms of sound production, and signal design differ notably among echolocators. The term click is loosely used to describe acoustic signals that 
are short and do not exhibit any structured changes in frequency over time. Birds, odontocetes, shrews, tenrecs, and echolocating rousette bats use click-type biosonar signals. Contrarily, laryngeal echolocating bats produce acoustic signals characterized by structured changes in frequency over time, such as downward sweeps (Figure 2). In our discussion of bird echolocation signals, we will follow Pye's definition of clicks as "broadband impulse sounds with no clearly defined coherent 'carrier' frequency, no evidence of frequency modulation and an amplitude pattern that is rapid and transient" (Pye, 1980). We will use "click" to define the basic signal unit of bird echolocation and "click burst" to describe two or more clicks produced in rapid succession.

\section{ECHOLOCATION SIGNAL DESIGN IN OILBIRDS}

The first description of Oilbird sonar emissions was based on field recordings of naturally behaving birds flying within a cave $(90 \mathrm{~m}$ from entrance) at Caripe, Venezuela (Griffin, 1953). Signals from sequences where only one bird was detected on the microphone were described as stereotyped and readily audible to humans at a distance up to $180 \mathrm{~m}$ from the bird. Each click consisted of only a few sound waves, and thus was of very brief duration (ca. $1 \mathrm{~ms}$ ), with most energy between 6 and $10 \mathrm{kHz}$ (Table 1). Notably, clicks were not emitted at a regular rate, but in bursts of 2-6+ clicks, with nearly constant within-burst click intervals of $2.6 \mathrm{~ms}$ and little within-burst variation (Griffin, 1953).

Konishi and Knudsen (1979) reported that Oilbird signal energy was unevenly distributed from 1 to $15 \mathrm{kHz}$, with most energy from 1.5 to $2.5 \mathrm{kHz}$, coincident with the birds' most sensitive area of hearing (Konishi and Knudsen, 1979). The auditory threshold curve, derived from cochlear evoked potentials, showed maximum sensitivity at $2 \mathrm{kHz}$, with a roughly $20 \mathrm{~dB}$ decline per octave for higher frequencies, indicating that Oilbirds should be deaf, or at least largely insensitive, to sounds above $6 \mathrm{kHz}$ (Figure 3). Konishi and Knudsen (1979) included obstacle avoidance experiments revealing that Oilbirds successfully detect and avoid disks of $\geq 20 \mathrm{~cm}$ diameter but may have failed to detect disks $\leq 10 \mathrm{~cm}$ diameter. However, discs with diameters $\leq 20 \mathrm{~cm}$ were presented in an array where individual disks were spaced at 5 times the chosen disc diameter. This means that trials with discs $\leq 10 \mathrm{~cm}$ likely affected the ability of the Oilbirds to negotiate

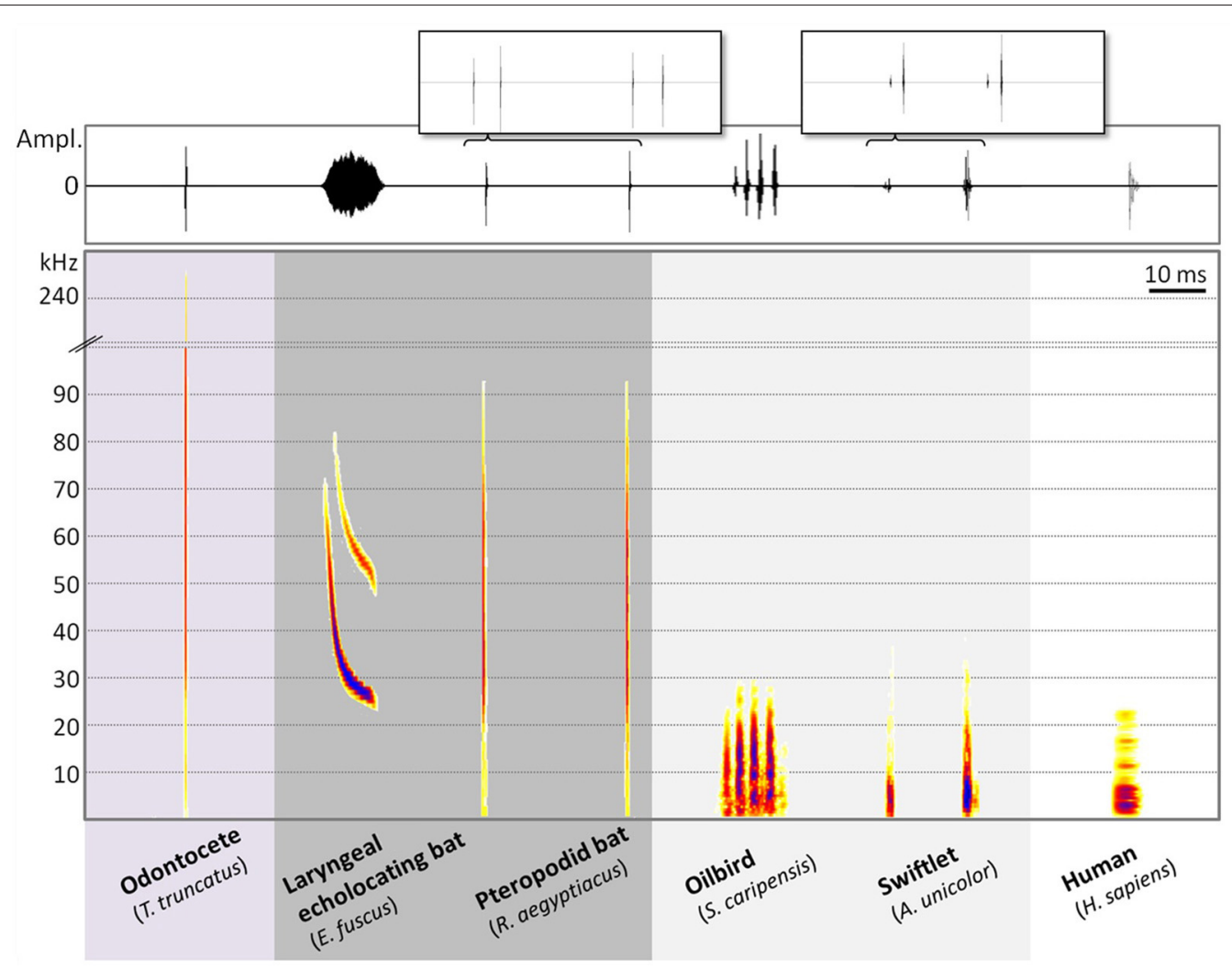

FIGURE 2 | Composite waveform (top) and spectrogram (bottom) of echolocation signals from 6 vertebrate species: common bottlenose dolphin (Tursiops truncatus), sample rate $(f \mathrm{~s})=500 \mathrm{kHz}$; laryngeal echolocating bat (Eptesicus fuscus), fs $=250 \mathrm{kHz}$; tongue-clicking pteropodid bat (Rousettus aegyptiacus), fs $=250 \mathrm{kHz}$; Oilbird (Steatornis caripensis), fs $=75 \mathrm{kHz}$; swiftlet (Aerodramus unicolor), fs $=250 \mathrm{kHz}$ and echolocating blind human subject (Homo sapiens), $\mathbf{f s}=\mathbf{4 8} \mathbf{~ k H z}$. Top inserts both have total time scales of $300 \mathrm{~ms}$ and illustrate the double clicks often emitted by echolocating Rousettus spp. and most echolocating swiftlet species. Bat and bird recordings made by Signe Brinkløv, dolphin recording courtesy of Magnus Wahlberg, human recording courtesy of Cynthia Moss. Spectrograms were created in BatSound v. 4 using an FFT size of 256, except for those from $R$. aegyptiacus and $S$. caripensis, for which an FFT size of 128 was used. All spectrograms were made using $98 \%$ overlap. Colors indicates relative amplitude going from low (light color) to high (darker color). Note the interrupted frequency scale between 100 and $230 \mathrm{kHz}$. Waveform amplitudes have all been normalized to the same level. 
Table 1 | Summary of Oilbird (Steathornis caripensis) echolocation click parameters described in previous literature.

\begin{tabular}{llllll}
\hline & \multicolumn{2}{c}{ Click parameters } & Recording site & Recording condition & System frequency response \\
\cline { 2 - 4 } & Duration (ms) & Frequency (kHz) & & \\
\hline Griffin, 1953 & 1 & $6-10$ & Field Venezuela & Inside cave & Within $\pm 6 \mathrm{~dB} 50-15,000 \mathrm{~Hz}$ \\
Konishi and Knudsen, 1979 & $>20$ & $1.5-2.5$ & Aviary Trinidad & Birds hovering & Flat 50-20,000 Hz \\
Suthers and Hector, 1985 & $40-50$ & No data & Laboratory Trinidad & Handheld birds, blindfolded & Flat 100-40,000 Hz \\
\hline
\end{tabular}

Despite similar frequency responses across recording systems, data for click duration and frequencies with most energy are noticeably different. Griffin (1953) reported that a $2 \mathrm{kHz}$ high pass filter was used in the analysis of some recordings but that such a filter was implemented only after verification that the unfiltered recordings had no appreciable energy components below $2 \mathrm{kHz}$.

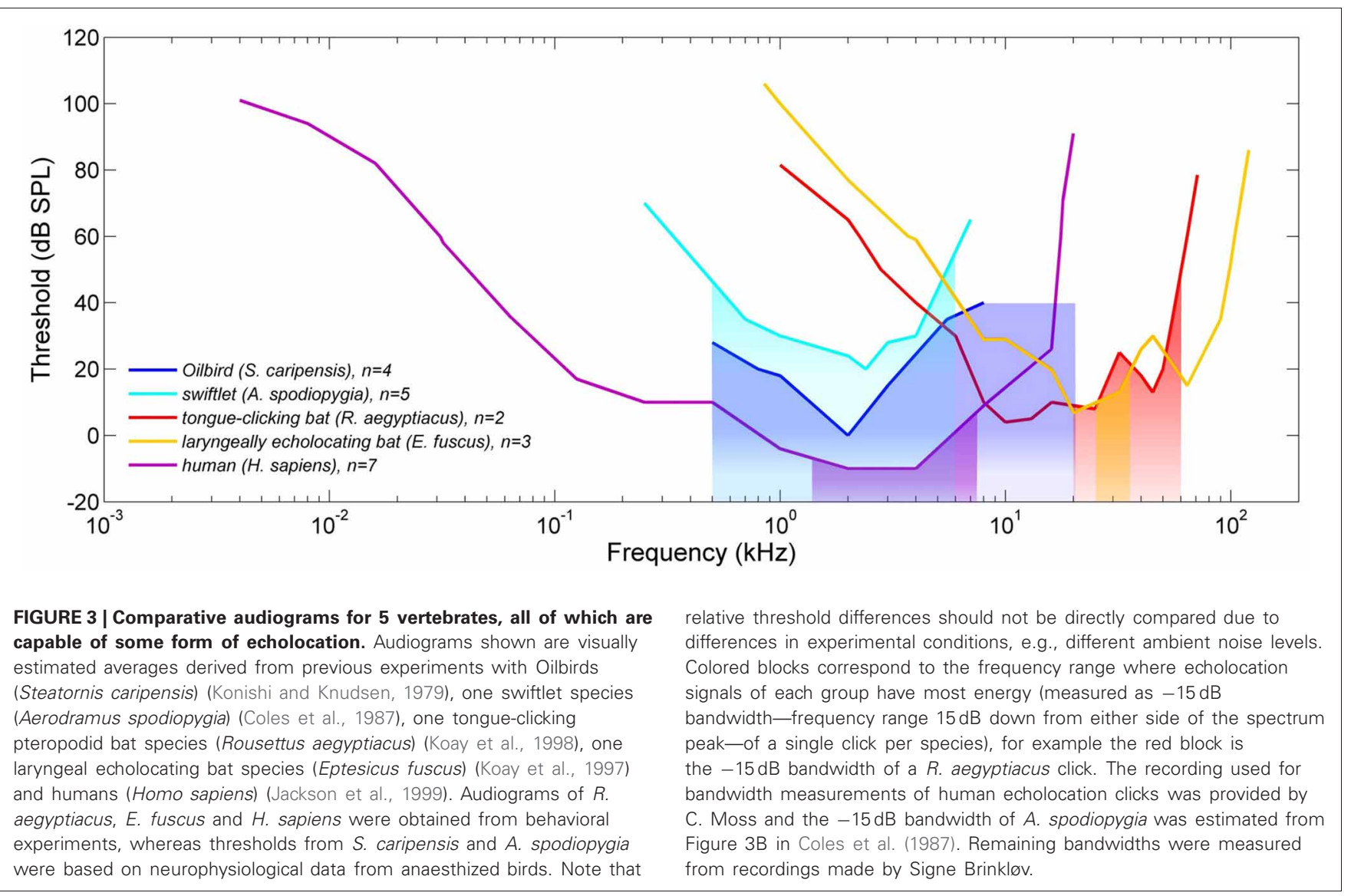

a course through such an array, as the inter-disc spaces $(\leq 50 \mathrm{~cm})$ were only half of the birds' wingspan. As in bats and whales, an increase in signal repetition rate was noted prior to avoidance manoeuvres (Konishi and Knudsen, 1979).

Suthers and Hector (1983) reported that Oilbirds acoustically detected obstacles as small as $3.2 \mathrm{~cm}$ in diameter using signals with most energy at $0.5-3.0 \mathrm{kHz}$. They suggested that the birds used either continuous pulsatile signals (durations of $40-80 \mathrm{~ms}$ ) or, occasionally, much shorter pulses emitted at repetition rates ranging from only a few every second to $12 \mathrm{~s}^{-1}$ (Suthers and Hector, 1985). From handheld birds, Suthers and Hector (1983) estimated signal intensity as $\sim 100 \mathrm{~dB}$ SPL rms at $20 \mathrm{~cm}$ to $1 \mathrm{~m}$ distance. There are no published quantitative estimates of signal intensity in free-flying Oilbirds and we do not know if the birds can adjust the intensity of their signals, as do laryngeal echolocating bats and toothed whales.

\section{ECHOLOCATION SIGNAL DESIGN IN SWIFTLETS}

Echolocation has been confirmed in 16 species of swiftlets (Chantler et al., 1999) and existing descriptions of swiftlet echolocation signals are more congruent, even across recording conditions, than those for Oilbirds (Table 2). Swiftlet clicks are composed of frequencies completely within the human auditory range, with most energy between 1 and $10 \mathrm{kHz}$.

With notable exceptions, most swiftlet species emit both single and double clicks (Thomassen et al., 2004). Double clicks, or click-pairs, are emitted more frequently than single clicks (up to $75 \%$ of the time) and so close together that they, as the 
Brinkløv et al.

Oilbird and swiftlet echolocation

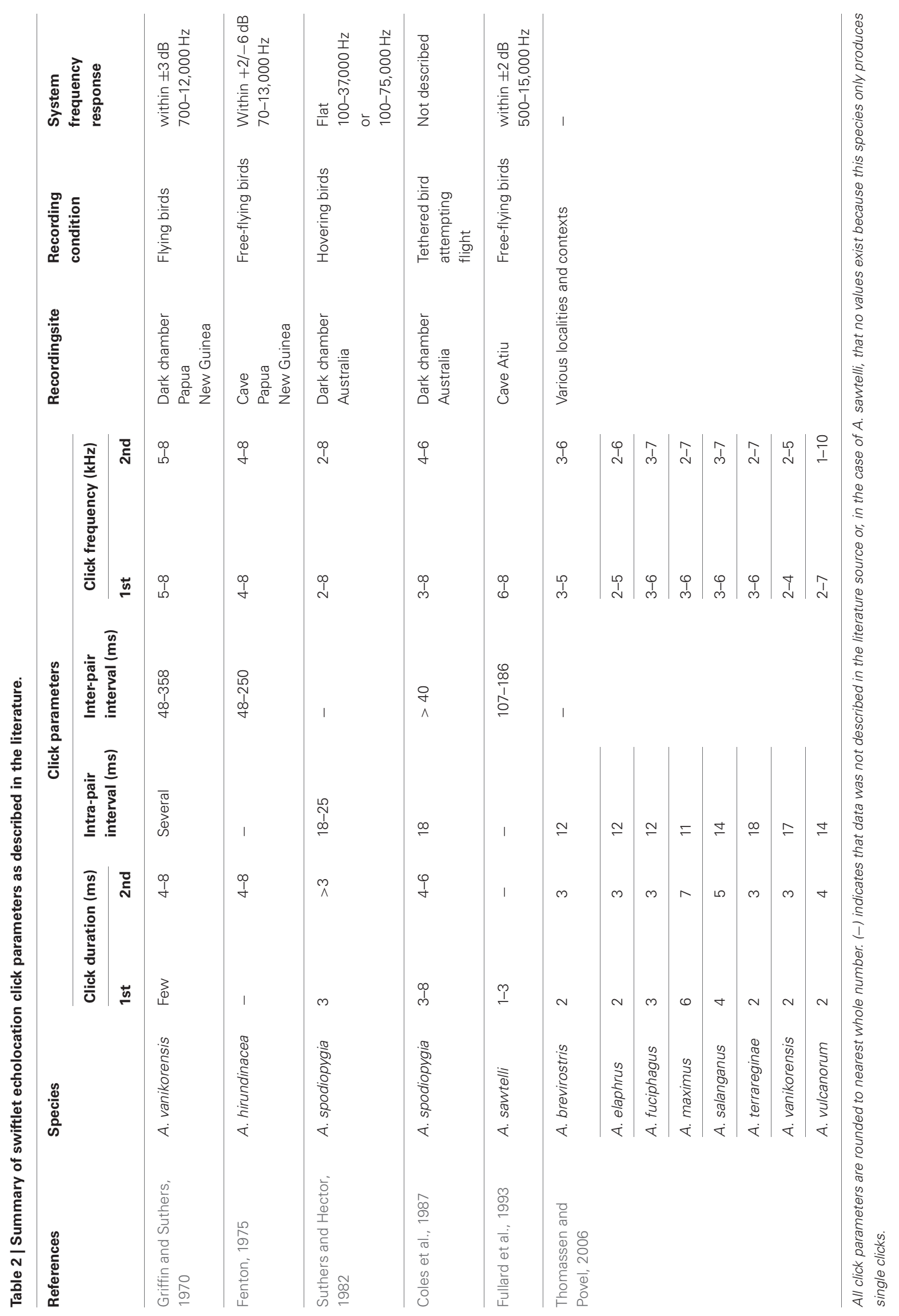

Frontiers in Physiology | Integrative Physiology

May 2013 | Volume 4 | Article 123 | 6 
click-bursts of Oilbirds, sound like a single sound to human ears (Griffin and Suthers, 1970). Each click within a pair lasts 1-8 ms, with the second often of higher amplitude (Griffin and Suthers, 1970; Suthers and Hector, 1982; Coles et al., 1987). Clicks in a pair are separated by 11-25 ms (Table 2).

Swiftlet clicks have been described as highly stereotyped, varying little in design regardless of situation (Thomassen and Povel, 2006). However, swiftlets increase click repetition rate when facing complex challenges, such as approaching obstacles (Griffin and Suthers, 1970; Coles et al., 1987) or their nests (Signe Brinkløv, pers. obs. of A. unicolor in railway tunnels). Fullard et al. (1993) found that birds emitted higher repetition rates when entering caves than when exiting caves or flying from closed to more open space. Meanwhile, no context-dependent changes were found in signal frequency (Fullard et al., 1993), as compared to the adaptive, context-dependent changes in signal frequency found in many laryngeal echolocating bats.

\section{CURRENT KNOWLEDGE OF THE ECHOLOCATION ABILITIES OF BIRDS \\ ECHOLOCATION AND HEARING ABILITIES OF OILBIRDS}

Oilbirds have only a single middle ear bone in each ear (as opposed to the three found in mammals), a simple cochlea (Martin, 1990), and thus, like other birds, are expected to be insensitive to frequencies above $10 \mathrm{kHz}$ (Dooling et al., 2000). As noted above, Oilbirds emit conspicuous echolocation signals at frequencies well within the human hearing range and little to no energy above $20 \mathrm{kHz}$. However, it remains unclear whether most frequency content falls below $5 \mathrm{kHz}$ (Konishi and Knudsen, 1979), or above $5 \mathrm{kHz}$ as described in the earlier field study (Griffin, 1953). Konishi and Knudsen (1979) argued that main frequency content at $6-10 \mathrm{kHz}$, as reported by Griffin (1953), would result in a mismatch between emitter and receiver. However, Konishi and Knudsen (1979) displayed data points on Oilbird auditory sensitivity up to but not beyond $8 \mathrm{kHz}$. None of the studies described above seem limited by the frequency range of the recording systems used (Table 1) and so the upper limit of sound frequencies tested by Konishi and Knudsen (1979) was apparently based on the reasonable assumption that Oilbirds do not hear frequencies above $8 \mathrm{kHz}$. Konishi and Knudsen (1979) also suggest that Oilbirds exhibit little or no directional hearing at frequencies up to $4 \mathrm{kHz}$ and beyond, as predicted by the size of the birds' heads and lack of any external ear structures. While Griffin's (1953) work was done in the field, Konishi and Knudsen's (1979) descriptions are from captive animals. If Oilbirds can change the frequency content of their clicks by shifting signal energy to higher frequencies in the presence of loud ambient low frequency noise, this might occur more often in the field than in captivity.

Existing descriptions of echolocation signal parameters from Oilbirds also reveal discrepancies concerning signal duration (Table 1) and raise questions about how clicks in general are defined by bioacousticians. Griffin (1953) described Oilbird biosonar signals as having a minimum duration of $1 \mathrm{~ms}$, thus referring to a click as the smallest subunit within a burst of sonar emissions. Konishi and Knudsen (1979) used 'click' to describe each $>20 \mathrm{~ms}$ burst of pulses, reasoning based on their recordings that each burst comprises a complex waveform with pulsatile elements rather than a series of discrete pulses. They noted increases in repetition rate between rather than within burst units as birds approached a variety of obstacles. They also argued that because each burst, rather than each burst subunit (i.e., click), is registered as a single, coherent unit by the human ear, by extension they would be registered as a single sound at the bird's more simple ear. Suthers and Hector (1985; their Figure 5) also referred to each click as a burst of several amplitude peaks rather than the subunits within each burst. The number of subunits within a burst varies (Griffin, 1953; Signe Brinkløv, pers. obs.), but whether this variation is of any functional significance to the birds is unknown. The well rounded, if conflicting, data set on Oilbird echolocation makes this species especially attractive for future integrative lab and field-based studies.

\section{ECHOLOCATION AND HEARING ABILITIES OF SWIFTLETS}

Swiftlet clicks appear to have most energy over a $1-10 \mathrm{kHz}$ frequency range. Based on rule of thumb calculations, the birds should only detect objects $\geq 34 \mathrm{~mm}$ diameter, but can apparently detect objects as small as $6.3 \mathrm{~mm}$ diameter (metal rods) at levels above chance (Griffin and Suthers, 1970; Griffin and Thompson, 1982). Corroborating this, Smyth and Roberts (1983) reported a detection threshold of 10-20 mm, while Fenton (1975) found that $A$. hirundinacea detected vertical rods down to $10 \mathrm{~mm}$ diameter and potentially even smaller. These data suggest that swiftlets receive useful echo information via the higher frequency portions of their clicks, even though these components contain less energy. However, for this to be plausible the birds must hear, at least to some extent, higher frequencies. This is not supported by data from single neuron recordings from the midbrain auditory nucleus of Collocalia spodiopygia, which indicate best frequency thresholds from 0.8 to $4.7 \mathrm{kHz}$ (Coles et al., 1987).

Whatever the ultimate size limit of object detection by swiftlet biosonar, observations of increased click repetition rates from birds approaching their nests in the wild (Fullard et al., 1993; Signe Brinkløv, pers. obs.) suggest that swiftlets use echolocation to locate their nests. And, because swiftlet nests are $50-100 \mathrm{~mm}$ in diameter (Coles et al., 1987; Chantler et al., 1999), even a conservative detection size threshold would indicate that the nest itself should be readily detectable by swiftlet echolocation.

\section{SINGLE AND DOUBLE SWIFTLET BIOSONAR CLICKS: A WEST-EAST TRANSITION?}

A. sawtelli, endemic to Atiu, one of the Cook Islands, only emits single clicks, giving rise to the hypothesis of an evolutionary West-East transition from double clicks to the obligate emission of single echolocation clicks (Fullard et al., 1993, 2010). However, Thomassen et al. (2004) reported that several relatively western species of swiftlets can also emit single clicks. Conversely, $A$. vanikorensis in the more centrally located Phillipines and New Guinea appears to emit only double clicks (Thomassen et al., 2004).

Whether single and double clicks serve specific, even separate functions that are correlated to certain behaviors is also unknown, as is whether swiftlets can actively control which type is emitted. Interestingly, although assumed to echolocate, we are unaware of scientific accounts of echolocation in the 
Polynesian Swiftlet, A. leucophaeus, at the far eastern geographic distribution of swiftlets. A. leucophaeus is missing from recent attempts to resolve the controversial swiftlet phylogeny but ostensibly includes three subspecies found on Tahiti, Mo'orea, and the Marquesas in French Polynesia (Chantler et al., 1999). More knowledge about the genetic relationship between $A$. leucophaeus and the geographically close single click emitter A. sawtelli, along with information about the nature of $A$. leucophaeus echolocation clicks, could help elucidate why some swiftlets only emit single clicks and possibly the underlying functional reasons for the use of single and double clicks.

Egyptian rousettes ( $R$. aegyptiacus, Pteropodidae) use double clicks to point their sound beam to the right and left of a target to trade localization over detection (Yovel et al., 2010). Rousette bats echolocate using tongue clicks and this means of echolocating contrasts with the situation in laryngeal echolocating bats, which direct their sonar beam with high precision directly at the target (Jakobsen and Surlykke, 2010). It would be interesting to see whether the double clicks of swiftlets function like those of Rousettus.

\section{ECHOLOCATION FOR ORIENTATION, ECHOLOCATION FOR FOOD DETECTION?}

Echolocating birds use clicks dominated by low frequencies (Konishi and Knudsen, 1979; Coles et al., 1987), limiting their ability to detect small targets. A target reflects echoes only if its cross section is at least roughly one-third as large as the wavelengths impinging on it (Pye, 1980; Jakobsen et al., 2013). Therefore, bird echolocation clicks are not suited for detection of smaller objects such as insect prey $<2-3 \mathrm{~cm}$ in diameter. Although echolocating birds appear to lack the highly specialized and flexible echolocation abilities of laryngeal echolocating bats and toothed whales they are clearly adept at maneuvering and locating their nests within the dark interior of their cave roosts.

Several anecdotal observations suggest that Oilbirds occasionally echolocate outside caves and around fruiting palm trees (Konishi and Knudsen, 1979; Suthers and Hector, 1985). Snow (1961) reported that he never heard clicks from Oilbirds feeding at night. Staff at the Asa Wright Nature Center in Trinidad provided us with contradictory reports indicating that Oilbirds do click while flying around fruiting palms (Signe Brinkløv, pers. comm.). As Oilbirds eat fruit that is considerably larger than the insect prey of swiftlets (Snow, 1961; Bosque et al., 1995) and often visit trees with a conspicuous shape (e.g., palms), the use of echolocation to find food remains an enticing possibility.

One of us (M. Brock Fenton) has spent considerable time listening for echolocation clicks from swiftlets on Papua New Guinea (A. hirundinacea) and in Australia (A. spodiopygia) and never heard clicks from night-flying birds except as they returned to their roosts. Notably, however, Atiu Swiftlets (A. sawtelli) and Papuan Swiftlets (A. papuensis) click not only in their caves but also outside at night, apparently while hunting insect prey in low light (Fullard et al., 1993; Chantler et al., 1999; Price et al., 2005). In swiftlets, echolocation may thus be more advanced in some species than others, but this is highly speculative. If so, the relationship between two click/one click flexibility and the use of echolocation outside the cave would be one area to explore.
Oilbirds and swiftlets both orient visually when ambient light conditions are sufficient, as indicated by the absence of echolocation sounds altogether under such conditions and suggested by their oversize eyes relative to other birds. However, the absence of data on light levels taken concurrently with acoustic recordings make it unclear under exactly what conditions the birds should be expected to rely on echolocation over vision.

\section{ECHOLOCATION IN A SOCIAL CONTEXT}

Inside their roosts, echolocating Oilbirds and swiftlets must deal with a host of reverberations from cave surfaces as well as a cacophony of clicks from conspecifics. Besides orientation, bird echolocation signals may serve a role in communication. Laryngeal echolocating bats react to the feeding buzzes emitted by con- and hetero-specifics moments before contact with an airborne insect (Gillam et al., 2007; Übernickel et al., 2013), and change their echolocation behavior when flying in groups as opposed to alone (Obrist, 1995; Ratcliffe et al., 2004; Brinkløv et al., 2009).

In addition to echolocation clicks, Oilbirds and swiftlets produce a range of more tonal signals (Suthers and Hector, 1985; Thomassen and Povel, 2006). For example, Oilbird social squawks resemble a prolonged click burst, including up to $20+$ subunits, and are often emitted as several birds fly together (Suthers and Hector, 1985). Such signals likely serve a communicative function to birds flying in close proximity (e.g., as agonistic "honks" to prevent collision, Signe Brinkløv, pers. obs.), analogous to social functions suggested for bat buzzes (i.e., call rates $>100$ calls/s) emitted outside the context of prey-capture (Bayefsky-Anand et al., 2008). Moreover, both Oilbirds and swiftlets appear to forage socially, as indicated by observations of birds arriving at feeding locations and returning to caves in groups of 2 or more individuals (Snow, 1961; Signe Brinkløv, pers. obs.). Swiftlets should be able to maintain visual contact during their daytime foraging bouts, but for nocturnal Oilbirds, biosonar signals may facilitate social cohesion in flight.

There is enough inter-specific variation in swiftlet biosonar clicks to render them species-specific, primarily based on interspecific variation of maximum click frequency (Thomassen and Povel, 2006). It is plausible then that swiftlet echolocation clicks could be used in conspecific recognition, potentially of relevance where several species have overlapping geographical distributions and may either share or compete for access to caves. However, the social signals of swiftlets are also species-specific (Thomassen and Povel, 2006) and may serve equally well or better for this and other purposes. On a similar note, the morphological asymmetry of the Oilbird syrinx may allow for individual recognition during vocal communication. Individual differences in vocal tract asymmetry have been suggested as a means for Oilbirds to distinguish echoes originating from their own echolocation signals from those clicks and echoes originating from their roostmates (Suthers and Hector, 1988).

\section{WHY CLICK?}

Many species of non-echolocating swiftlets and swifts (Apodidae) are acoustically conspicuous to human observers. Two examples are the "screaming" parties of Common Swifts on the wing 
(Apus apus; Lack, 1956) and the conspicuous flight chirps of Chimney Swifts (Chaetura pelagica; Bouchard, 2005). Indeed, the syringes of most non-Oscine birds (e.g., Oilbirds and swiftlets) are well-suited to producing a wide range of acoustic signals (Suthers and Hector, 1985). Why then, do Oilbirds and swiftlets use clicks for echolocation? As Buchler and Mitz (1980) noted, there is no obvious reason why two signals with the same power spectra, one a click, the other a frequency-modulated signal, should differ in their basic utility in echolocation. If anything, single-sweep, frequency-modulated signals may be advantageous, allowing the echolocator to produce a longer signal, with more overall energy, in which a particular frequency is essentially time-stamped (Simmons and Stein, 1980).

We propose that echolocating birds use click-type signals for echolocation because they are short in duration, permitting detection of objects even at very short distances (i.e., with no overlap between signal and echo). At the same time click-type signals do not require the laryngeal specializations observed in bats necessary to produce a sufficiently short frequency-modulated signal. In the non-echolocating Chimney Swifts, none of the frequency-modulated and/or harmonic signals reported by Bouchard (2005) would be short enough to serve as an effective echolocation signal in a cave roost. Additionally or alternatively, clicks may be more effective biosonar signals for detection of objects at greater distances because they may be (i) less energetically expensive to produce using the syrinx and (ii) louder than other signal designs using the same energy input. We note that despite several attempts to uncover any morphological and neurological specializations, none have yet been found in the syringeal morphology, hearing abilities, middle ear morphology or higher processing centers (auditory nuclei) of Oilbirds or echolocating swiftlets that set them apart from non-echolocating birds (Konishi and Knudsen, 1979; Thomassen, 2005; Iwaniuk et al., 2006).

\section{EVOLUTION OF BIRD ECHOLOCATION}

A recent phylogenomic study of the birds embeds swiftlets within what appears to be the paraphyletic Caprimulgiformes, the avian order that includes Oilbirds (Hackett et al., 2008). Nevertheless, the most parsimonious evolutionary scenario consists of three independent originations of syringeal echolocation in birds, once in the precursor to Oilbirds and twice within the swiftlets (Figure 1). Both groups use echolocation to gain access to roosting sites and nests in caves and deep gorges, where they may be protected from some predators. This common ecological variable may have provided evolutionary impetus for the multiple appearances of echolocation within the clade. An analogous connection between cave-dwelling and use of echolocation seems to be present in rousette bats (Giannini and Simmons, 2003). One avenue of future research would be investigations of the species-specific relationships between the visual systems, presence or absence of echolocation, and preferred light-level of the cave roost within an evolutionary context using the comparative method. Information about the ontogeny of echolocation is at present also completely unknown.
Echolocation almost certainly originated independently in Apodiformes and Caprimulgiformes and likely evolved independently within two distinct lineages of swiftlets (Price et al., 2005; Thomassen et al., 2005). The inaccessibility of many species of swiftlets and resulting lack of genetic and acoustic data means that the evolutionary pathways of swiftlet echolocation remain to be unravelled. Increased molecular sampling and systematic documentation of swiftlet echolocation abilities will be necessary to further resolve their phylogenetic history. Such research would help to clarify species limits, answer questions about the evolution of obligate single click emitting species and address the predominance of those species that produce both double and single biosonar clicks.

Most echolocating bats forage only at night (Neuweiler, 1984), spending the day resting in their roosts. Echolocating swiftlets, like the vast majority of birds, are diurnal foragers (Chantler et al., 1999). Thus, despite their use of cave roosts and similarities in feeding ecology (i.e., the capture of flying insects on the wing) (Fenton, 1975), swiftlets and similar-sized insect-eating bats are not likely to compete with one another directly, due to temporal separation of foraging activities. Similarly, there is no evidence that either echolocating bats or swiftlets feed on one another. Oilbirds and rousette bats exploit a similar niche, albeit on different continents. Interestingly, both Oilbirds and rousette bats are nocturnal frugivores, and both use click-type echolocation and dark roosts during the day (Griffin et al., 1958; Snow, 1961). In the New-World tropics, where Oilbirds and a number of smaller frugivorous New World leaf-nosed bats (Phyllostomidae) overlap both spatially and temporally when foraging, there appears to be very little overlap in fruit preference between these groups. Oilbirds consume large fruits, often with large seeds that are later regurgitated (Snow, 1962), while phyllostomid bats are much smaller and feed preferentially on fruits with small seeds that are chewed or expelled while eating (Wendeln et al., 2000; Mello et al., 2011).

\section{FUTURE RESEARCH STEPS}

Further studies of the echolocation systems of birds will be valuable additions to the ever-expanding and progressive field of bat and toothed whale echolocation research. State-of-the-art lightweight field equipment (e.g., multi-microphone arrays) and custom-designed computational software should provide better quality recordings of biosonar signals from Oilbirds and swiftlets. Experiments could be designed to compare signals of birds flying in different contexts, for example, field versus captivity, open space versus cave interior and multiple versus single birds, to help resolve current uncertainties about signal design. Further, such recordings should help identify who says what, when, and where even in complex situations where several birds are flying together and provide useful clues about echolocation in a social context.

The highly specialized echolocation systems of toothed whales and laryngeal echolocating bats have provided and continue to provide fascinating insights into the mammalian auditory system and active sensory processes in animals across taxa. By comparison, echolocation in birds has received almost no attention. This is perhaps because we have implicitly regarded bird biosonar as unsophisticated and, thus, less interesting. Perhaps, less cynically, 
it is simply because bats are found everywhere, save past the treeline and on a few isolated Oceanic islands, while echolocating birds are far less wide-spread and in general more difficult to gain access to than are bats.

Deployment of portable tags with hydrophones and accelerometers has contributed greatly to the understanding of toothed whale acoustic behavior in deep waters where the animals roam beyond visual inspection (Madsen et al., 2005; Johnson et al., 2007; Jensen et al., 2011). Corresponding on-board archival microphone tags would be ideal to assess the level of any active and adaptive control over sonar signal characteristics in birds, clarify the potential role of bird echolocation in the context of in-flight social interactions and allow us to determine if Oilbirds echolocate while foraging. In-flight GPS recorders have already been used to track movements of Oilbirds in the field (Holland et al., 2009) and their large size makes Oilbirds ideal subjects for the first acoustic tagging study of echolocating birds. Further, direct endoscopic visualization of syringeal mechanisms is now possible (Goller and Larsen, 1997), as are in vitro neuromuscular preparations to study the biomechanic mechanisms involved in avian and mammalian sound production (Elemans et al., 2004, 2011). Such techniques could be put to use in better understanding biosonar click production in Oilbirds and swiftlets.

\section{REFERENCES}

Bayefsky-Anand, S., Skowronski, M. D., Fenton, M. B., Korine, C., and Holderied, M. W. (2008). Variations in the echolocation calls of the European free-tailed bat. J. Zool. 275, 115-123. doi: 10.1111/j.14697998.2008.00418.x

Bosque, C., Ramirez, R., and Rodriguez, D. (1995). The diet of the Oilbird in Venezuela. Ornitologia Neotropical 6, 67-80.

Bouchard, J. (2005). The Role of Acoustic Signals in Flying Chimney Swifts, Chaetura Pelagica. M.Sc. thesis, Department of Biology, University of Western Ontario, London, ON.

Brinkløv, S., Kalko, E. K. V., and Surlykke, A. (2009). Intense echolocation calls from two 'whispering' bats, Artibeus jamaicensis and Macrophyllum macrophyllum (Phyllostomidae). J. Exp. Biol. 212, 11-20. doi: 10.1242/jeb.023226

Brooke, R. K. (1970). Taxonomic and evolutionary notes on the subfamilies, tribes, genera and subgenera of the swifts (Aves: Apodidae). Durb. Mus. Nov. 9, 13-24.

Brooke, R. K. (1972). Generic limits in old world Apodidae and Hirundinidae. Bull. Br. Ornithol. Club 92, 53-57.

Buchler, E. R. (1976). The use of echolocation by the wandering shrew (Sorex vagrans).

The tongue-clicking pteropodid bat $R$. aegyptiacus uses echolocation to detect and discriminate objects better than previously suspected (Yovel et al., 2011). Echolocation in birds may be similarly underappreciated. Moreover, a deeper understanding of echolocation in birds, rousette bats, and shrews and tenrecs would have its own rewards. Echolocation by blind people is now more common and better understood, and comparisons to nonhuman echolocators using similar click-type signals may help us learn more about and improve human biosonar. In a broader sense, understanding animal biosonar across taxa will undoubtedly reveal similarities and differences across different groups of animals that have independently evolved biosonar systems with respect to all aspects of their biology, from ecology and evolution, to the neurophysiology and biomechanics of sound production and echo processing.

\section{ACKNOWLEDGMENTS}

Signe Brinkløv was funded by The Danish Council For Independent Research | Natural Sciences (FNU) and John M. Ratcliffe by FNU and the Oticon Foundation while preparing this manuscript. Biologists and field guides at the Asa Wright Nature Center, Trinidad, and the University of Colombo and FOGSL (Field Ornithology Group of Sri Lanka) have contributed to several relevant behavioral observations and ongoing studies of Oilbirds and swiftlets (A. unicolor).

Elemans, C. P. H., Spierts, I. L. Y. Müller, U. K., van Leeuwen, J. L., and Goller, F. (2004). Superfast muscles control dove's trill. Nature 431, 146. doi: 10.1038/431146a

Elemans, C. P. H., Mead, A. F., Jakobson, L., and Ratcliffe, J. M. (2011). Superfast muscles set maximum call rate in echolocating bats. Science 333, 1885-1888. doi: 10.1126/science. 1207309

Fenton, M. B. (1975). Acuity of echolocation in Collocalia hirundinacea (Aves: Apodidae), with comments on the distributions of echolocating swiftlets and molossid bats. Biotropica 7, 1-7.

Forsman, K. A., and Malmquist, M. G. (1988). Evidence for echolocation in the common shrew, Sorex araneus. J. Zool. Soc. Lond. 216, 655-662. doi: 10.1111/j.14697998.1988.tb02463.x

Fullard, J. H., Barclay, R. M. R., and Thomas, D. W. (1993). Echolocation in free-flying Atiu Swiftlets (Aerodramus sawtelli). Biotropica 25, 334-339.

Fullard, J. H., Barclay, R. M. R., and Thomas, D. W. (2010). Observations on the behavioural ecology of the Atiu Swiftlet Aerodramus sawtelli. Bird Cons. Int. 20, 385-391.

Giannini, N. P., and Simmons, N. B. (2003). A phylogeny of megachiropteran bats (Mammalia:
Chiroptera: Pteropodidae) based on direct optimization analysis of one nuclear and four mitochondrial genes. Cladistics 19, 496-511. doi: 10.1016/ j.cladistics.2003.09.002

Gillam, E. H., Ulanovsky, N., and McCracken, G. F. (2007). Rapid jamming avoidance in biosonar. Proc. R. Soc. B. 274, 651-660. doi: 10.1098/rspb.2006.0047

Goller, F., and Larsen, O. N. L. (1997). A new mechanism of sound generation in songbirds. Proc. Natl. Acad. Sci. U.S.A. 94, 14787-14791.

Gould, E. (1965). Evidence for echolocation in the Tenrecidae of Madagascar. Proc. Am. Phil. Soc. 109, 352-360.

Gould, E., Negus, N. C., and Novick, A. (1964). Evidence for echolocation in shrews. J. Exp. Zool. 156, 19-37.

Griffin, D. R. (1944). Echolocation by blind men, bats and radar. Science 29, 589-590. doi: 10.1126/science.100.2609.589

Griffin, D. R. (1953). Acoustic orientation in the Oilbird, Steatornis. Proc Natl. Acad. Sci. U.S.A. 39, 884-893.

Griffin, D. R. (1958). Listening in the Dark. New Haven, CT: Yale University Press.

Griffin, D. R., Novick, A., and Kornfield, M. (1958). The sensitivity of echolocation in the fruit bat, Rousettus. Biol. Bull. 115, 107-113. 
Griffin, D. R., and Suthers, R. A. (1970). Sensitivity of echolocation in cave swiftlets. Biol. Bull. 139, 495-501.

Griffin, D. R., and Thompson, T. (1982). Echolocation by cave swiftlets. Behav. Ecol. Sociobiol. 10, 119-123. doi: 10.1007/BF00300171

Hackett, S. J., Kimball, R. T., Reddy, S., Bowie, R. C. K., Braun, E. L., Braun, M. J., et al. (2008). A phylogenomic study of birds reveals their evolutionary history. Science 320, 1763-1768. doi: 10.1126/science.1157704

Holland, R. A., Wikelski, M., Kümmeth, F., and Bosque, C. (2009). The secret life of Oilbirds: new insights into the movement ecology of a unique avian frugivore. PLoS ONE 4:e8264. doi: 10.1371/journal.pone.0008264

Iwaniuk, A. N., Clayton, D. H., and Wylie, D. R. W. (2006). Echolocation, vocal learning, auditory localization and the relative size of the avian auditory midbrain nucleus (MLd). Behav. Brain Res. 167, 305-317. doi: 10.1016/j.bbr.2005.09.015

Jackson, L. L., Heffner, R. S., and Heffner, H. E. (1999). Free-field audiogram of the Japanese macaque (Macaca fuscata). J. Acoust. Soc. Am. 106, 3017-3023.

Jakobsen, L., and Surlykke, A. (2010). Vespertilionid bats control the width of their biosonar sound beam dynamically during prey pursuit. Proc. Natl. Acad. Sci. U.S.A. 107, 13930-13935. doi: 10.1073/pnas.1006630107

Jakobsen, L., Ratcliffe, J. M., and Surlykke, A. (2013). Convergent acoustic field of view in echolocating bats. Nature 493, 93-96. doi: 10.1038/nature11664

Jensen, F. H., Marrero Perez, J., Johnson, M. P., Aguilar Soto, N., and Madsen, P. T. (2011). Calling under pressure: short-finned pilot whales make social calls during deep foraging dives. Proc. R. Soc. B. 278, 3017-3025. doi: $10.1098 / \mathrm{rspb} .2010 .2604$

Johnson, M., Hickmott, L. S., Aguilar Soto, N., and Madsen, P. T. (2007). Echolocation behaviour adapted to prey in foraging Blainville's beaked whale (Mesoplodon densirostris). Proc. R. Soc. B. 275, 133-139. doi: 10.1098/rspb.2007.1190

Kellogg, W. N., and Kohler, R. (1952). Reactions of the porpoise to ultrasonic frequencies. Science 116, 250-252. doi: 10.1126/science.116.3010.250

Koay, G., Heffner, H. E., and Heffner, R. S. (1997). Audiogram of the big brown bat (Eptesicus fuscus).
Hear. Res. 105, 202-210. doi: 10.1016/S0378-5955(96)00208-0

Koay, G., Heffner, R. S., and Heffner, H. E. (1998). Hearing in a megachiropteran fruit bat (Rousettus aegyptiacus). J. Comp. Psychol. 112, 371-382. doi: 10.1037/0735-7036. 112.4.371

Konishi, M., and Knudsen, E. I. (1979). The Oilbird: hearing and echolocation. Science 204, 425-427. doi: 10.1126/science.441731

Lack, D. (1956). Swifts in a Tower. London: Methuen.

Leonard, M. L., and Fenton, M. B. (1984). Echolocation calls of Euderma maculatum (Vespertilionidae): use in orientation and communication. J. Mammal. 65, 122-126.

Madsen, P. T., Johnson, M., Aguilar de Soto, N., Zimmer, W. M. X. and Tyack, P. (2005). Biosonar performance of foraging beaked whales (Mesoplodon densirostris). J. Exp. Biol. 208, 181-194. doi: 10.1242/jeb.01327

Martin, G. R. (1990). Birds by Night. London: T. and A. D. Poyser

Martin, G. R., Rojas, L. M., Ramírez, Y., and McNeil, R. (2004). The eyes of Oilbirds (Steatornis caripensis): pushing a the limits of sensitivity. Naturwissenschaften 91, 26-29. doi: 10.1007/s00114-003-0495-3

Medway, L., and Pye, J. D. (1977). "Echolocation and the systematics of swiftlets," in Evolutionary Ecology, eds B. Stonehouse and C. Perrins (Baltimore, MD: University Park Press), 225-238.

Medway, L., and Wells, D. R. (1969). Dark orientation by the Giant Swiftlet Collocalia gigas. Ibis 111, 609-611. doi: 10.1111/j.1474919X.1969.tb02570.x

Mello, M. A. R., Marquitti, F. M. D., Guimaraes, P. R. Jr., Kalko, E. K. V., Jordano, P., and de Aguiar, M. A. M. (2011). The missing part of seed dispersal networks: structure and robustness of batfruit interactions. PLOS ONE 6:e17395. doi: 10.1371/journal. pone. 0017395

Møhl, B., Wahlberg, M., Madsen, P. T., Heerfordt, A., and Lund, A. (2003). The monopulsed nature of sperm whale clicks. J. Acoust. Soc. Am. 114, 1143-1154.

Möhres, F. P., and Kulzer, E. (1956). Über die Orientierung der Flughund (ChiropteraPteropodidae). Z. Vergl. Physiol. 38, $1-29$.

Neuweiler, G. (1984). Foraging, echolocation and audition in bats. Naturwissenschaften 71, 446-455.
Nicol, J. A. C., and Arnott, H. J. (1974). Tapeta lucida in the eyes of goatsuckers (Caprimulgidae). Proc. R. Soc. B. 187, 349-352.

Norris, K. S., Prescott, J. H., AsaDorian, P. V., and Perkins, P. (1961). An experimental demonstration of echo-location behavior in the porpoise, Tursiops truncatus (Montagu). Biol. Bull. 120, 163-176.

Novick, A. (1958). Orientation in Paleotropical bats. II. Megachiroptera. J. Exp. Zool. 137, 443-462. doi: 10.1002/jez.1401370305

Obrist, M. K. (1995). Flexible bat echolocation: the influence of individual, habitat and conspecifics on sonar signal design. Behav. Ecol. Sociobiol. 36, 207-219. doi: 10.1007/BF00177798

Päckert, M., Martens, J., Wink, M., Feigl, A., and Tietze, D. T. (2012). Molecular phylogeny of Old World swifts (Aves: Apodiformes, Apodidae, Apus and Tachymarptis) based on mitochondrial and nuclear markers. Mol. Phylogen. Evol. 63, 606-616. doi: 10.1016/j.ympev.2012.02.002

Poulter, T. C. (1963). Sonar signals of the sea lion. Science 139, 753-755. doi: 10.1126/science.139.3556.753

Price, J. J., Johnson, K. P., and Clayton, D. H. (2004). The evolution of echolocation in swiftlets. J. Avian Biol. 35, 135-143. doi: 10.1111/j.0908-8857.2004.03182.x

Price, J. J., Johnson, K. P., Bush, S. E., and Clayton, D. H. (2005). Phylogenetic relationships of the Papuan Swiftlet Aerodramus papuensis and implications for the evolution of avian echolocation. Ibis 147, 790-796. doi: 10.1111/j.1474-919X.2005.00467.x

Pye, J. D. (1980). "Echolocation signals and echoes in air," in Animal Sonar Systems, eds R.-G. Busnel and J. F. Fish (New York, NY: Plenum Press), 309-353.

Ratcliffe, J. M., ter Hofstede, H. M., Avila-Flores, R., Fenton, M. B., McCracken, G. F., Biscardi, S., et al. (2004). Conspecifics influence call design in the Brazilian free-tailed bat, Tadarida brasiliensis. Can. J. Zool. 82, 966-971. doi: 10.1139/ z04-074

Renoulf, D., and Davies, M. B. (1982). Evidence that seals may use echolocation. Nature 300, 635-637. doi: $10.1038 / 300635 \mathrm{a} 0$

Roca, R. L. (1994). Oilbirds of Venezuela: Ecology and Conservation. Cambridge, MA: Publications of the Nuttall Ornithological Club.
Rydell, J., and Arlettaz, R. (1994). Low-frequency echolocation enables the bat Tadarida teniotis to feed on tympanate insects. Proc. R. Soc. Lond. B 257, 175-178. doi: 10.1098/rspb.1994.0112

Schusterman, R. J., Kastak, D., Levenson, D. H., Reichmuth, C. J., and Southall, B. L. (2000) Why pinnipeds don't echolocate. J. Acoust. Soc. Am. 107, 2256. doi: 10.1121/1.428506

Siemers, B. M., Schauermann, G., Turni, H., and von Merten, S. (2009). Why do shrews twitter? Communication or simple echo-based orientation. Biol. Lett. 5, 593-596. doi: 10.1098/rsbl.2009.0378

Simmons, J. A., and Stein, R. A. (1980). Acoustic imaging in bat sonar: echolocation signals and the evolution of echolcoation. J. Comp. Physiol. A. 135, 61-84.

Smyth, D. M., and Roberts, J. R. (1983). The sensitivity of echolocation by the Grey Swiftlet Aerodramus spodiopygius. Ibis 125, 339-345. doi: 10.1111/j.1474919X.1983.tb03119.x

Snow, D. W. (1961). The natural history of the oilbird, Steatornis caripensis, in Trinidad, W. I. Part 1. General behavior and breeding habits. Zoologica 46, 27-48.

Snow, D. W. (1962). The natural history of the oilbird, Steatornis caripensis, in Trinidad, W. I. Part 2. Population, breeding ecology and food. Zoologica 47, 199-221.

Supa, M., Cotzin, M., and Dallenbach, K. M. (1944). "Facial Vision": the perception of obstacles by the blind. Am. J. Psychol. 57, 133-183.

Suthers, R. A., and Hector, D. H. (1982). Mechanism for the production of echolocating clicks by the Grey Swiftlet, Collocalia spodiopygia. J. Comp. Physiol. 148, 457-470. doi: 10.1007/ BF00619784

Suthers, R. A., and Hector, D. H (1983). Mechanisms of sonar pulse production by Oilbirds. J. Acoust. Soc. Am. 74(Suppl. 1), 31. doi: $10.1121 / 1.2020912$

Suthers, R. A., and Hector, D. H. (1985). The physiology of vocalization by the echolocating Oilbird, Steatornis caripensis. J. Comp. Physiol. A 156, 243-266. doi: 10.1007/BF00610867

Suthers, R. A., and Hector, D. H. (1988). "Individual variation in vocal tract resonance may assist oilbirds in recognizing echoes of their own sonar clicks," in Animal Sonar: Processes and Performance, eds P. E. 
Nachtigall and P. W. B. Moore (New York, NY: Plenum Press), 87-91.

Thaler, L., Arnott, S. R., and Goodale, M. A. (2011). Neural correlates of natural human echolocation in early and late blind echolocation experts. PLoS ONE 6:e20162. doi: 10.1371/journal. pone. 0020162

Thomas, B. T. (1999). "Family Steatonithidae (Oilbird)," in Handbook of the Birds of the World. Vol. 5. Barn Owls to hummingbirds, eds J. del Hoyo, A. Elliott, and J. Sargatal (Barcelona: Lynx), 244-251.

Thomassen, H. A. (2005). Swift as Sound - Design and Evolution of the Echolocation System in Swiftlets (Apodidae: Collocaliini). Ph.D. thesis, Leiden University.

Thomassen, H. A., and Povel, G. D. E. (2006). Comparative and phylogenetic analysis of the echo clicks and social vocalisations of swifts and swiftlets (Aves: Apodidae). Biol. J. Linn. Soc. 88, 631-643. doi: 10.1111/j.1095-8312. 2006.00648.x

Thomassen, H. A., Djasim, U. M., and Povel, G. D. E. (2004). Echo click design in swiftlets: single as well as double clicks. Ibis 146, 173-174. doi: 10.1111/j.1474-919X.2004.00237.x

Thomassen, H. A., den Tex, R.-J., de Bakker, M. A. G., and Povel, G. D. E. (2005). Phylogenetic relationships of some swifts and swiftlets; a multi locus approach. Mol. Phylogenet. Evol. 37, 264-277. doi: 10.1016/j.ympev. 2005.05.010

Thomassen, H. A., Wiersema, A. T., de Bakker, M. A. G., de Knijff, P., Hetebrij, E., and Povel, G. D. E. (2003). A new phylogeny of swiftlets (Aves: Apodidae) based on cytochrome b DNA. Mol. Phylogenet. Evol. 29, 86-93.

Thompson, D. B., and Suthers, R. A. (1983). Acuity of echolocation on the Oilbird, Steatornis caripensis. J. Acoust. Soc. Am. 74(Suppl. 1), 31. doi: 10.1121/ 1.2020913

Tomasi, T. E. (1979). Echolocation by the short-tailed shrew Blarina brevicauda. J. Mammal. 60, 751-759. doi: $10.2307 / 1380190$

Übernickel, K., Tschapka, M., and Kalko, E. K. V. (2013). Selective eavesdropping behaviour in three neotropical bat species. Ethology 119, 66-76. doi: 10.1111/eth.12038

Videler, J. J., Stamhuis, E. J., and Povel, G. D. (2004). Leading-edge vortex lifts swifts. Science 306, 1960-1962. doi: $10.1126 /$ science. 1104682

von Humboldt, A. (1817). Mémoire sur le Guacharo de la caverne de Caripe. Recueil d'Obs. de Zool. E d'Anatomie no. 2.

Warrant, E. (2008). "Nocturnal vision," in The Senses: A Comprehensive Reference, Vol. 2, eds R. H. Masland and T. Albright (New York, NY: Academic Press). 53-86.

Wendeln, M. C., Runkle, J. R., and Kalko, E. K. V. (2000). Nutritional values of $14 \mathrm{fig}$ species and bat feeding preferences in Panama. Biotropica 32, 489-501. doi: 10.1111/ j.1744-7429.2000.tb00495.x

Yovel, Y., Falk, B., Moss, C. F., and Ulanovsky, N. (2010). Optimal localization by pointing off axis. Science 327, 701-704. doi 10.1126/science. 1183310

Yovel, Y., Geva-Sagiv, M., and Ulanovsky, N. (2011). Clickbased echolocation in bats: not so primitive after all. J. Comp.
Physiol. A. 197, 515-530. doi: 10.1007/s00359-011-0639-4

Conflict of Interest Statement: The authors declare that the research was conducted in the absence of any commercial or financial relationships that could be construed as a potential conflict of interest.

Received: 03 February 2013; accepted: 11 May 2013; published online: 28 May 2013.

Citation: Brinkløv S, Fenton $M B$ and Ratcliffe JM (2013) Echolocation in Oilbirds and swiftlets. Front. Physiol. 4:123. doi: 10.3389/fphys.2013.00123

This article was submitted to Frontiers in Integrative Physiology, a specialty of Frontiers in Physiology.

Copyright (c) 2013 Brinkløv, Fenton and Ratcliffe. This is an open-access article distributed under the terms of the Creative Commons Attribution License, which permits use, distribution and reproduction in other forums, provided the original authors and source are credited and subject to any copyright notices concerning any third-party graphics etc. 